1 Universidade Federal de Pernambuco (UFPE) -

Recife (PE), Brasil.

marilia_gabrielle170@

hotmail.com

2 Universidade Federal de Pernambuco (UFPE) Recife (PE), Brasil.

marciacarrera@hotmail.com

3 Universidade Federal de Pernambuco (UFPE) Recife (PE), Brasil. marquesap@hotmail.com

4 Universidade Federal de Pernambuco (UFPE) Recife (PE), Brasil. ssmendonca@gmail.com

\section{Idosos longevos: avaliação da qualidade de vida no domínio da espiritualidade, da religiosidade e de crenças pessoais}

\author{
Long-lived elderly: assessment of quality of life in the field of \\ spirituality, religiousness and personal beliefs
}

Marília Gabrielle Santos Nunes ${ }^{\mathbf{1}}$, Márcia Carrera Campos Leal2, Ana Paula de Oliveira Marques³, Sarah de Souza Mendonça 4

RESUMO Este estudo tem como objetivo avaliar a qualidade de vida no domínio da espiritualidade, da religiosidade, de crenças pessoais e fatores associados em idosos longevos. Para isso, foi utilizado o questionário World Health Organization Quality of Life - Spirituality, Religiousness and Personal Beliefs, através de um estudo descritivo, transversal, com a participação de 100 idosos. Verificou-se que provavelmente a qualidade de vida esteja relacionada com a autoestima e com o bem-estar pessoal/espiritual. Neste âmbito, profissionais de saúde precisam estar engajados e incorporar este conhecimento, principalmente aqueles atrelados aos serviços de Atenção Primária à Saúde.

PALAVRAS-CHAVE Idoso de 80 anos ou mais. Espiritualidade. Qualidade de vida. Religião.

ABSTRACT This study aims to evaluate the quality of life in the field of spirituality, religiousness, personal beliefs and associated factors in long-lived elderly. For this purpose, the World Health Organization Quality of Life - Spirituality, Religiousness and Personal Beliefs questionnaire was used, through a descriptive, cross-sectional study, with the participation of 100 elderly people. It has been found that quality of life is probably related to self-esteem and personal/spiritual wellbeing. In this context, health professionals need to be engaged and incorporate this knowledge, especially those linked to Primary Health Care services.

KEYWORDS Elderly aged 80 and over. Spirituality. Quality of life. Religion. 


\section{Introdução}

O envelhecimento populacional é um tema que vem ganhando amplo enfoque no cenário mundial, tornando-se muito significativo, tanto do ponto de vista científico quanto do das políticas públicas. Nas últimas décadas, toma grandes proporções, em razão do aumento da expectativa de vida, que tem como consequência a longevidade (BRITO ET AL., 2013).

Esse novo cenário nacional exige do Estado a formulação e a implementação de políticas públicas que assistam essa população e, especialmente, de um sistema de saúde que esteja preparado para atender às especificidades dessa demanda. Para tanto, deverá contar com profissionais que compreendam o processo de envelhecer em todas as suas dimensões (biológicas, sociais, psicológicas e espirituais), respeitando a autonomia que o idoso possui sobre o seu cuidado (CUNHA ET AL., 2012).

Segundo Mello (2013), a partir do aumento do segmento populacional dos idosos no Brasil, um aspecto de grande interesse e acentuado crescimento no meio acadêmico inclui os estudos acerca da qualidade de vida e da longevidade. De acordo com a literatura, a qualidade de vida do idoso está relacionada com a autoestima e com o bem-estar pessoal/ espiritual. Além disto, está centrada em uma série de fatores, como capacidade funcional, nível socioeconômico, estado emocional, interação social, atividade intelectual, autocuidado, suporte familiar, o próprio estado de saúde, estilo de vida, satisfação com atividades diárias e espiritualidade (VECCHIA, 2005).

Na prática do profissional de saúde, cada vez mais tem se tornado fortalecida a relação entre espiritualidade e saúde como um fator constante. Para Volcan et al. (2003), uma condição importante para o reconhecimento da espiritualidade no campo da saúde foi a introdução da dimensão espiritual no conceito de saúde da Organização Mundial da Saúde (OMS), no qual esta passa a ser caracterizada como bem-estar biopsicossocial e espiritual.

Segundo Rohr (2011), a espiritualidade é um fenômeno profundamente humano, que não se encaixa em uma completa definição. Por isto, é difícil encontrar um consenso na elaboração de seu conceito. Desta forma, o autor esclarece que a espiritualidade é uma das cinco dimensões que fazem parte do ser humano, e não se pode concebê-la como uma dimensão isolada das demais.

As cinco dimensões básicas que regem a alma humana são: 1) a dimensão física, que é o ser físico-biológico, do qual nem temos percepção; 2) a dimensão sensorial, representada pelas sensações físicas, através dos cinco sentidos; 3) a dimensão emocional, que abrange os nossos estados emocionais, a nossa psique; 4) a dimensão mental, que inclui o racional e o lógico, a capacidade de refletir, de questionar todas as coisas - inclusive a si mesmo; e 5) a espiritualidade, que é a mais difícil de ser examinada e não pode ser confundida com a religiosidade, pois, diferem-se no que diz respeito à intervenção de Deus sobre as coisas e ao tipo de organização social, aspectos que não são enquadrados na dimensão espiritual (ROHR, 2011).

De acordo com Gaarder (2005), as religiões costumam ditar os valores morais, e estabelecem a relação entre o homem e um ser superior no qual este acredita. É comum, nas religiões, a crença em algo que ultrapassa o empírico, em algo divino, que pode ser um princípio abstrato, um estado de graça que a pessoa pode alcançar. O conceito de espiritualidade é uma busca pessoal para entender questões relacionadas à vida, ao seu sentido; sobre as relações com o sagrado ou com o transcendental, que podem ou não levar ao desenvolvimento de práticas religiosas (ROHR, 2012).

A espiritualidade não está necessariamente vinculada a uma crença em Deus; remete a uma questão universal e está baseada em um propósito de vida. Além disto, compartilha com a religiosidade a crença em uma divindade, mas não prega nenhuma específica. De outro modo, não descarta a possibilidade de que pessoas espiritualizadas possam acreditar em uma divindade específica A 
espiritualidade não afasta a ideia de que a fé religiosa possa ser uma forma específica de vivenciar a própria espiritualidade. Por outro lado, nem tudo o que se apresenta como religiosidade inclui a espiritualidade. Isto pode ser percebido quando a religiosidade estabelece doutrinas e inflexibilidades, mostrando-se intolerante aos outros tipos de fé e de crenças (ROHR, 2012).

Portanto, considerando que a qualidade de vida do idoso pode ser afetada tanto por estados de saúde (médico, social e mental) quanto por condições socioeconômicas e fatores do meio em que a pessoa vive ou interage (espiritualidade, relações familiares e de amizade). Então, mesmo que o indivíduo não tenha nenhuma doença instalada, isto não significa, necessariamente, que ele tem uma boa qualidade de vida. E o inverso também vale, pois existem pessoas que, embora sofram enfermidades crônicas, permanecem relativamente felizes, aceitando e convivendo bem com suas condições (COSTA, 2013).

Diante do exposto, o objetivo do presente estudo foi avaliar a qualidade de vida no domínio da espiritualidade, da religiosidade, de crenças pessoais e fatores associados, em idosos longevos assistidos pela Estratégia Saúde da Família.

\section{Material e métodos}

Trata-se de um estudo descritivo, quantitativo, de corte transversal, realizado no período de abril a agosto de 2015. Participaram da pesquisa 100 idosos com 80 anos ou mais, de ambos os sexos, que não estavam vinculados a nenhuma instituição, residentes na área de abrangência da microrregião 4.2 da cidade do Recife (PE), e cadastradas nas Unidades de Saúde da Família (USF).

A coleta de dados foi realizada por meio de questionário aplicado aos idosos, em entrevistas face a face, baseando-se na qualidade de vida no domínio da espiritualidade, da religiosidade e de crenças pessoais.
Foram utilizadas perguntas referentes às características demográficas e socioeconômicas (idade, em anos; raça/cor; situação conjugal; sexo; escolaridade, em anos de estudo; rendimento mensal individual; e religião); com relação à situação de saúde autopercebida e à morbidade diagnosticada em prontuário.

$\mathrm{O}$ estado mental foi avaliado através do Miniexame do Estado Mental (MEEM). O apoio social foi verificado por meio da escala de redes sociais de Lubben, a Lubben Social Network Scale (LSNS). Para a avaliação de depressão, foi utilizada uma escala denominada Geriatric Depression Scale (GDS), e para a avaliação da satisfação pessoal, foi utilizada a Escala de Satisfação com a Vida.

Para a avaliação da qualidade de vida, da espiritualidade, da religiosidade e de crenças pessoais, utilizou-se o World Health Organization Quality of Life - Spirituality, Religiousness and Personal Beliefs (WHOQOL-SRPB), instrumento da OMS desenvolvido para verificar de que forma estes aspectos estão relacionados à qualidade de vida na saúde e na assistência à saúde. Este instrumento possui 32 itens, 8 facetas, 1 índice geral do domínio e 8 fatoriais pela média dos itens, resultados de 4 a 20 .

A tabulação dos dados foi efetuada com o auxílio do programa Excel. Os dados foram analisados com o auxílio do programa Statistical Package for the Social Sciences, versão 19.0. (SPSS Inc., Chicago, Illinois, Estados Unidos).

$\mathrm{Na}$ descrição das proporções, procedeu-se a uma aproximação da distribuição binomial, a distribuição normal pelo intervalo de confiança de $95 \%$. Na comparação das proporções, utilizaram-se os testes de Mantel-Haenszel e o Quadrado de Pearson (ou tendência linear).

A análise multivariada foi utilizada para estimar a contribuição independente de cada variável para o nível de espiritualidade/ religiosidade e crenças pessoais. Para a construção do modelo, foram testadas as variáveis da análise bivariada com probabilidades 
de $20 \%$. Para tanto, empregou-se a regressão logística binária, por meio do método Backward. Para efeito de interpretação, o limite do erro tipo I foi de até $5 \%(\mathrm{p} \leq 0,05)$.

A pesquisa foi aprovada pelo Comitê de Ética e Pesquisa com Seres Humanos da Universidade Federal de Pernambuco (Certificado de Apresentação para Apreciação Ética no 34900514000005208), em conformidade com a Resolução n ${ }^{\circ} 466 / 12$, do Ministério da Saúde, referente ao desenvolvimento de pesquisa científica envolvendo seres humanos. A pesquisa foi integralmente financiada pelos próprios pesquisadores.

\section{Resultados}

As principais características da amostra, em relação aos dados demográficos e socioeconômicos, foram: $77 \%$ do sexo feminino; $34 \%$ da raça branca; $46 \%$ com escolaridade de 1 a 4 anos; $63 \%$ viúvos; $76 \%$ com renda de 1 a 2 salários mínimos; $73 \%$ aposentados; e $72 \%$ da religião católica.

Verificou-se que a maioria dos homens eram casados ou tinham companheiras, o que foi significativamente evidenciado com $\mathrm{p}<0,001$. Além disso, observou-se que a maioria das idosas eram aposentadas $(\mathrm{p}=0,004)$.

A tabela 1 apresenta uma análise na qual os domínios foram classificados da seguinte maneira: espiritualidade/religiosidade alta, se a média da pontuação fosse maior ou igual a 4; espiritualidade/religiosidade moderada, se média da pontuação no domínio fosse maior ou igual a 2 e menor do que 4 ; e espiritualidade/religiosidade baixa, se média da pontuação no domínio fosse menor do que 2 .

Tabela 1. Classificação da espiritualidade/religiosidade/crenças por condições sociais na microrregião 4.2 da cidade do Recife (PE), Brasil, 2016

\begin{tabular}{|c|c|c|c|c|c|}
\hline \multicolumn{6}{|c|}{ ERC } \\
\hline & \multicolumn{2}{|c|}{ Moderada } & \multicolumn{2}{|c|}{ Alta } & \multirow{2}{*}{ P-Valor ${ }^{\star}$} \\
\hline & Frequência & $\%$ & Frequência & $\%$ & \\
\hline Faixa Etária & & & & & 0,331 \\
\hline Menos de 85 Anos & 11 & 20,4 & 43 & 79,6 & \\
\hline 85 Anos ou Mais & 6 & 13 & 40 & 87 & \\
\hline Nível de Escolaridade & & & & & 0,449 \\
\hline Analfabeto & 5 & 16,7 & 25 & 83,3 & \\
\hline Baixa Escolaridade & 6 & 13 & 40 & 87 & \\
\hline Alta Escolaridade & 6 & 25 & 18 & 75 & \\
\hline Situação Conjugal & & & & & 0,634 \\
\hline Estar Casado(a)/Ter Companheiro(a) & 3 & 13,6 & 19 & 86,4 & \\
\hline $\begin{array}{l}\text { Não Estar Casado(a)/Não Ter } \\
\text { Companheiro(a) }\end{array}$ & 14 & 17,9 & 64 & 82,1 & \\
\hline Renda & & & & & 0,183 \\
\hline Menos de 1 Salário Mínimo & 5 & 33,3 & 10 & 66,7 & \\
\hline De 1 a 2 Salários Mínimos & 11 & 14,5 & 65 & 85,5 & \\
\hline Mais de 2 Salários Mínimos & 1 & 11,1 & 8 & 88,9 & \\
\hline
\end{tabular}




\begin{tabular}{|c|c|c|c|c|c|}
\hline \multicolumn{6}{|l|}{ Tabela 1. (cont.) } \\
\hline \multicolumn{5}{|l|}{ Raça } & \multirow[t]{5}{*}{0,969} \\
\hline Branca & 6 & 17,6 & 28 & 82,4 & \\
\hline Preta & 3 & 15 & 17 & 85 & \\
\hline Amarela & 1 & 25 & 3 & 75 & \\
\hline Parda & 7 & 16,7 & 35 & 83,3 & \\
\hline \multicolumn{5}{|l|}{ Religião } & \multirow[t]{5}{*}{0,424} \\
\hline Católica Apostólica Romana & 15 & 20,8 & 57 & 79,2 & \\
\hline Evangélica & 2 & 8 & 23 & 92 & \\
\hline Espírita & 0 & 0 & 2 & 100 & \\
\hline Sem Religião ou Não Declarada & 0 & 0 & 1 & 100 & \\
\hline \multicolumn{5}{|l|}{ Depressão } & \multirow[t]{3}{*}{0,153} \\
\hline Presente & 7 & 18,9 & 30 & 81,1 & \\
\hline Ausente & 10 & 15,9 & 53 & 84,1 & \\
\hline \multicolumn{5}{|l|}{ Satisfação com a Vida } & \multirow[t]{3}{*}{0,864} \\
\hline Satisfeito & 13 & 15,5 & 71 & 84,5 & \\
\hline Insatisfeito & 4 & 25 & 12 & 75 & \\
\hline \multicolumn{5}{|l|}{ Saúde Autopercebida } & \multirow[t]{6}{*}{0,317} \\
\hline Excelente & 0 & 0 & 5 & 100 & \\
\hline Muito Boa & 0 & 0 & 7 & 100 & \\
\hline Boa & 3 & 11,1 & 24 & 88,9 & \\
\hline Regular & 12 & 23,5 & 39 & 76,5 & \\
\hline Ruim & 2 & 20 & 8 & 80 & \\
\hline \multicolumn{5}{|l|}{ Apoio Social } & \multirow[t]{3}{*}{0,030} \\
\hline Boa Rede Social & 9 & 12,2 & 65 & 87,8 & \\
\hline Rede Social Insuficiente & 8 & 30,8 & 18 & 69,2 & \\
\hline
\end{tabular}

Fonte: Elaboração própria.

*Há indício de associação estatística nos casos em que o P-Valor for menor do que 0,05. Foi realizado o Teste Qui-Quadrado com correção computacional para pequenos valores.

Para realizar os testes de associação, a variável idade foi categorizada em duas faixas: idosos com até 85 anos e idosos com 85 anos ou mais.

De acordo com a tabela 1, os idosos que tinham boa rede social, atribuíam um maior valor a espiritualidade/religiosidade/ crenças, tendo sido encontrado valor significativo $\mathrm{p}=0,03$.

Após a análise da variável dependente, conforme os critérios definidos (espiritualidade/religiosidade/crenças), cada um dos domínios foi analisado separadamente para verificar as suas respectivas relações com as demais variáveis do estudo (condições sociodemográficas e clínicas). Os domínios que apresentaram resultados estatisticamente significantes foram as facetas paz e totalidade \& integração.

Observou-se que, para a faceta sentido na vida, aqueles idosos que não tinham depressão relataram-na alta $(\mathrm{p}=0,042)$, assim como os idosos que possuíam baixa escolaridade $(\mathrm{p}=0,038)$. 
A tabela 2 demonstra que os idosos com renda inferior a um salário mínimo apresentaram maior sentimento de equilíbrio entre a mente, o corpo e a alma, de forma a criar harmonia entre ações, pensamentos e sentimentos $(\mathrm{p}=0,021)$. Foi observado, ainda, que os idosos que se mostravam mais satisfeitos com a vida, igualmente, puderam experimentar esse sentimento de equilíbrio e integração, com valor estatisticamente significante $(p=0,022)$. Entre os idosos que possuíam uma boa rede social, a faceta totalidade \& integração foi significativamente mais elevada $(\mathrm{p}=0,018)$. Ainda de acordo com a tabela 2, percebe-se que os indivíduos que não eram diabéticos e não possuíam osteoartrose, quando comparados com aqueles que possuíam tais doenças, os primeiros apresentaram melhor escore na análise dessa faceta ( $\mathrm{p}=0,021$ e $\mathrm{p}=0,015$, respectivamente), na comparação entre saudáveis e doentes.

Tabela 2. Faceta totalidade \& integração segundo condições sociodemográficas e clínicas na microrregião 4.2 da cidade do Recife (PE), Brasil, 2016

\begin{tabular}{|c|c|c|c|c|c|}
\hline \multicolumn{6}{|c|}{ ERC } \\
\hline & \multicolumn{2}{|c|}{ Moderada } & \multicolumn{2}{|c|}{ Alta } & \multirow{2}{*}{ P-Valor ${ }^{\star}$} \\
\hline & Frequência & $\%$ & Frequência & $\%$ & \\
\hline Faixa Etária & & & & & 0,331 \\
\hline Menos de 85 Anos & 10 & 18,5 & 44 & 81,5 & \\
\hline 85 Anos ou Mais & 12 & 26,1 & 34 & 73,9 & \\
\hline Nível de Escolaridade & & & & & 0,756 \\
\hline Analfabeto & 8 & 26,7 & 22 & 73,3 & \\
\hline Baixa Escolaridade & 9 & 19,6 & 37 & 80,4 & \\
\hline Alta Escolaridade & 5 & 20,8 & 19 & 79,2 & \\
\hline Situação Conjugal & & & & & 0,926 \\
\hline Estar Casado(a)/Ter Companheiro(a) & 5 & 22,7 & 17 & 77,3 & \\
\hline $\begin{array}{l}\text { Não Estar Casado(a)/Não Ter } \\
\text { Companheiro(a) }\end{array}$ & 17 & 21,8 & 61 & 78,2 & \\
\hline Renda & & & & & 0,021 \\
\hline Menos de 1 Salário Mínimo & 7 & 46,7 & 8 & 53,3 & \\
\hline De 1 a 2 Salários Mínimos & 12 & 15,8 & 64 & 84,2 & \\
\hline Mais de 2 Salários Mínimos & 3 & 33,3 & 6 & 66,7 & \\
\hline Raça & & & & & 0,969 \\
\hline Branca & 5 & 14,7 & 29 & 85,3 & \\
\hline Preta & 5 & 25 & 15 & 75 & \\
\hline Amarela & 1 & 25 & 3 & 75 & \\
\hline Parda & 11 & 26,2 & 31 & 73,8 & \\
\hline Religião & & & & & 0,657 \\
\hline Católica Apostólica Romana & 15 & 20,8 & 57 & 79,2 & \\
\hline Evangélica & 7 & 28 & 18 & 72 & \\
\hline Espírita & 0 & 0 & 2 & 100 & \\
\hline Sem Religião ou Não Declarada & 0 & 0 & 1 & 100 & \\
\hline
\end{tabular}




\begin{tabular}{|c|c|c|c|c|c|}
\hline Depressão & & & & & 0,667 \\
\hline Presente & 9 & 24,3 & 28 & 75,7 & \\
\hline Ausente & 13 & 20,6 & 50 & 79,4 & \\
\hline Satisfação com a Vida & & & & & 0,022 \\
\hline Satisfeito & 15 & 17,9 & 69 & 82,1 & \\
\hline Insatisfeito & 7 & 43,8 & 9 & 56,3 & \\
\hline Saúde Autopercebida & & & & & 0,325 \\
\hline Excelente & 1 & 20 & 4 & 80 & \\
\hline Muito Boa & 0 & 0 & 7 & 100 & \\
\hline Boa & 5 & 18,5 & 22 & 81,5 & \\
\hline Regular & 15 & 29,4 & 36 & 70,6 & \\
\hline Ruim & 1 & 10 & 9 & 90 & \\
\hline Apoio Social & & & & & 0,018 \\
\hline Boa Rede Social & 12 & 16,2 & 62 & 83,8 & \\
\hline Rede Social Insuficiente & 10 & 38,5 & 16 & 61,5 & \\
\hline Hipertensão Arterial & & & & & 0,079 \\
\hline Ausente & 2 & 8,7 & 21 & 91,3 & \\
\hline Presente & 20 & 26 & 57 & 74 & \\
\hline Diabetes & & & & & 0,021 \\
\hline Ausente & 10 & 15,2 & 56 & 84,8 & \\
\hline Presente & 12 & 35,3 & 22 & 64,7 & \\
\hline Doenças Cardiovasculares & & & & & 0,262 \\
\hline Ausente & 14 & 19,2 & 59 & 80,8 & \\
\hline Presente & 8 & 29,6 & 19 & 70,4 & \\
\hline Osteoporose & & & & & 0,265 \\
\hline Ausente & 15 & 19,5 & 62 & 80,5 & \\
\hline Presente & 7 & 30,4 & 16 & 69,6 & \\
\hline Osteoartrose & & & & & 0,015 \\
\hline Ausente & 13 & 16,7 & 65 & 83,3 & \\
\hline Presente & 9 & 40,9 & 13 & 59,1 & \\
\hline Doenças Neurológicas & & & & & 0,912 \\
\hline Ausente & 21 & 22,1 & 74 & 77,9 & \\
\hline Presente & 1 & 20 & 4 & 80 & \\
\hline Doenças Respiratórias & & & & & 0,095 \\
\hline Ausente & 22 & 24,2 & 69 & 75,8 & \\
\hline Presente & 0 & 0 & 9 & 100 & \\
\hline Neoplasias & & & & & 0,630 \\
\hline Ausente & 21 & 21,6 & 76 & $\overline{78,4}$ & \\
\hline Presente & 1 & 33,3 & 2 & 66,7 & \\
\hline
\end{tabular}

Fonte: Elaboração própria.

*Há indício de associação estatística nos casos em que o P-Valor for menor do que 0,05. 
De acordo com a tabela 3, a não existência de depressão e a atribuição de um alto valor para a faceta paz foi estatisticamente significante $(\mathrm{p}=0,027)$. Os idosos que igualmente mostraram maior satisfação com a vida também atribuíram um alto significado à faceta paz, se comparados com aqueles que eram insatisfeitos $(p=0,029)$. O alto valor demonstrado pelas pessoas que estavam em paz consigo também foi associado com a boa rede social de que elas dispunham $(\mathrm{p}=0,017)$.

Tabela 3. Faceta paz segundo condições sociodemográficas e clínicas na microrregião 4.2 da cidade do Recife (PE), Brasil, 2016

\begin{tabular}{|c|c|c|c|c|c|c|c|}
\hline \multicolumn{8}{|c|}{ Faceta Paz } \\
\hline & \multicolumn{2}{|c|}{ Baixa } & \multicolumn{2}{|c|}{ Moderada } & \multicolumn{2}{|c|}{ Alta } & \multirow{2}{*}{ P-Valor* } \\
\hline & Frequência & $\%$ & Frequência & $\%$ & Frequência & $\%$ & \\
\hline Faixa Etária & & & & & & & 0,408 \\
\hline Menos de 85 Anos & 2 & 3,7 & 10 & 18,5 & 42 & 77,8 & \\
\hline 85 Anos ou Mais & 0 & 0 & 8 & 17,4 & 38 & 82,6 & \\
\hline Nível de Escolaridade & & & & & & & 0,085 \\
\hline Analfabeto & 0 & 0 & 7 & 23,3 & 23 & 76,7 & \\
\hline Baixa Escolaridade & 0 & 0 & 9 & 19,6 & 37 & 80,4 & \\
\hline Alta Escolaridade & 2 & 8,3 & 2 & 8,3 & 20 & 83,3 & \\
\hline Situação Conjugal & & & & & & & 0,328 \\
\hline $\begin{array}{l}\text { Estar Casado(a)/Ter } \\
\text { Companheiro(a) }\end{array}$ & 0 & 0 & 2 & 9,1 & 20 & 90,9 & \\
\hline $\begin{array}{l}\text { Não Estar Casado(a)/Não Ter } \\
\text { Companheiro(a) }\end{array}$ & 2 & 2,6 & 16 & 20,5 & 60 & 76,9 & \\
\hline Renda & & & & & & & 0,156 \\
\hline Menos de 1 Salário Mínimo & 0 & 0 & 4 & 26,7 & 11 & 73,3 & \\
\hline De 1 a 2 Salários Mínimos & 1 & 1,3 & 14 & 18,4 & 61 & 80,3 & \\
\hline Mais de 2 Salários Mínimos & 1 & 11,1 & 0 & 0 & 8 & 88,9 & \\
\hline Raça & & & & & & & 0,739 \\
\hline Branca & 1 & 2,9 & 6 & 17,6 & 27 & 79,4 & \\
\hline Preta & 0 & 0 & 2 & 10 & 18 & 90 & \\
\hline Amarela & 0 & 0 & 0 & 0 & 4 & 100 & \\
\hline Parda & 1 & 2,4 & 10 & 23,8 & 31 & 73,8 & \\
\hline Religião & & & & & & & 0,957 \\
\hline Católica Apostólica Romana & 2 & 2,8 & 13 & 18,1 & 57 & 79,2 & \\
\hline Evangélica & 0 & 0 & 5 & 20 & 20 & 80 & \\
\hline Espírita & 0 & 0 & 0 & 0 & 2 & 100 & \\
\hline $\begin{array}{l}\text { Sem Religião ou Não Decla- } \\
\text { rada }\end{array}$ & 0 & 0 & 0 & 0 & 1 & 100 & \\
\hline Depressão & & & & & & & 0,027 \\
\hline Presente & 2 & 5,4 & 10 & 27 & 25 & 67,6 & \\
\hline Ausente & 0 & 0 & 8 & 12,7 & 55 & 87,3 & \\
\hline
\end{tabular}


Tabela 3. (cont.)

\begin{tabular}{|c|c|c|c|c|c|c|c|}
\hline \multicolumn{7}{|l|}{ Satisfação com a Vida } & \multirow[t]{3}{*}{0,029} \\
\hline Satisfeito & 1 & 1,2 & 12 & 14,3 & 71 & 84,5 & \\
\hline Insatisfeito & 1 & 6,3 & 6 & 37,5 & 9 & 56,3 & \\
\hline Saúde Autopercebida & & & & & & & 0,415 \\
\hline Excelente & 0 & 0 & 0 & 0 & 5 & 100 & \\
\hline Muito Boa & 0 & 0 & 0 & 0 & 7 & 100 & \\
\hline Boa & 0 & 0 & 4 & 14,8 & 23 & 85,2 & \\
\hline Regular & 1 & 2 & 12 & 23,5 & 38 & 74,5 & \\
\hline Ruim & 1 & 10 & 2 & 20 & 7 & 70 & \\
\hline Apoio Social & & & & & & & 0,017 \\
\hline Boa Rede Social & 0 & 0 & 11 & 14,9 & 63 & 85,1 & \\
\hline Rede Social Insuficiente & 2 & 7,7 & 7 & 26,9 & 17 & 65,4 & \\
\hline Hipertensão Arterial & & & & & & & 0,295 \\
\hline Ausente & 1 & 4,3 & 2 & 8,7 & 20 & 87 & \\
\hline Presente & 1 & 1,3 & 16 & 20,8 & 60 & 77,9 & \\
\hline Diabetes & & & & & & & 0,085 \\
\hline Ausente & 1 & 1,5 & 8 & 12,1 & 57 & 86,4 & \\
\hline Presente & 1 & 2,9 & 10 & 29,4 & 23 & 67,6 & \\
\hline Doenças Cardiovasculares & & & & & & & 0,334 \\
\hline Ausente & 2 & 2,7 & 11 & 15,1 & 60 & 82,2 & \\
\hline Presente & 0 & 0 & 7 & 25,9 & 20 & 74,1 & \\
\hline Osteoporose & & & & & & & 0,032 \\
\hline Ausente & 1 & 1,3 & 10 & 13 & 66 & 85,7 & \\
\hline Presente & 1 & 4,3 & 8 & 34,8 & 14 & 60,9 & \\
\hline Osteoartrose & & & & & & & 0,350 \\
\hline Ausente & 2 & 2,6 & 12 & 15,4 & 64 & 82,1 & \\
\hline Presente & 0 & 0 & 6 & 27,3 & 16 & 72,7 & \\
\hline Doenças Neurológicas & & & & & & & 0,943 \\
\hline Ausente & 2 & 2,1 & 17 & 17,9 & 76 & 80 & \\
\hline Presente & 0 & 0 & 1 & 20 & 4 & 80 & \\
\hline Doenças Respiratórias & & & & & & & 0,757 \\
\hline Ausente & 2 & 2,2 & 17 & 18,7 & 72 & 79,1 & \\
\hline Presente & 0 & 0 & 1 & 11,1 & 8 & 88,9 & \\
\hline Neoplasias & & & & & & & 0,083 \\
\hline Ausente & 2 & 2,1 & 16 & 16,5 & 79 & 81,4 & \\
\hline Presente & 0 & 0 & 2 & 66,7 & 1 & 33,3 & \\
\hline
\end{tabular}

Fonte: Elaboração própria.

*Há indício de associação estatística nos casos em que o P-Valor for menor do que 0,05. 
Na tabela 4, diante de análise multivariada, através da regressão logística empregada com a faceta totalidade \& integração, permaneceram como fatores de risco independentes para a espiritualidade/religiosidade/crenças: renda, satisfação com a vida, apoio social, diabetes e osteoartrose. Em relação à faceta paz, os fatores de risco independentes para a espiritualidade/religiosidade/ crenças encontrados foram: depressão, satisfação com a vida, apoio social e a osteoporose.

Tabela 4. Fatores com associação estatística, segundo a análise bivariada, para espiritualidade/religiosidade/crenças, através das facetas paz e totalidade \& integração, do WHOQOL-SRPB. Recife (PE), Brasil, 2016

\begin{tabular}{|c|c|c|c|}
\hline \multirow{4}{*}{ Fatores de Risco } & Alta & Moderada & P-Valor ${ }^{\star}$ \\
\hline & \multicolumn{3}{|c|}{$n=100$} \\
\hline & \multicolumn{3}{|c|}{ Faceta Totalidade \& Integração } \\
\hline & Frequência (\%) & Frequência (\%) & \\
\hline Renda & & & 0,021 \\
\hline Menos de 1 Salário Mínimo & $8(53,3 \%)$ & $7(46,7 \%)$ & \\
\hline De 1 a 2 Salários Mínimos & $64(84,2 \%)$ & $12(15,8 \%)$ & \\
\hline Mais de 2 Salários Mínimos & $6(66,7 \%)$ & $3(33,3 \%)$ & \\
\hline Satisfação com a Vida & & & 0,022 \\
\hline Satisfeito & $69(82,1 \%)$ & $15(17,9 \%)$ & \\
\hline Insatisfeito & $9(56,3 \%)$ & $7(43,8 \%)$ & \\
\hline Apoio Social & & & 0,018 \\
\hline Boa Rede Social & $62(83,8 \%)$ & $12(16,2 \%)$ & \\
\hline Rede Social Insuficiente & $16(61,5 \%)$ & $10(38,5 \%)$ & \\
\hline Diabetes & & & 0,021 \\
\hline Ausente & $56(84,8 \%)$ & $10(15,2 \%)$ & \\
\hline Presente & $22(64,7 \%)$ & $12(35,3 \%)$ & \\
\hline Osteoartrose & & & 0,015 \\
\hline Ausente & $65(83,3 \%)$ & $13(16,7 \%)$ & \\
\hline Presente & $13(59,1 \%)$ & $9(40,9 \%)$ & \\
\hline
\end{tabular}

Faceta Paz

\begin{tabular}{|c|c|c|c|}
\hline \multicolumn{3}{|l|}{ Depressão } & \multirow[t]{3}{*}{0,017} \\
\hline Presente & $25(67,6 \%)$ & & \\
\hline Ausente & $55(87,3 \%)$ & & \\
\hline \multicolumn{3}{|l|}{ Satisfação com a Vida } & \multirow[t]{3}{*}{0,010} \\
\hline Satisfeito & $71(84,5 \%)$ & $13(15,5 \%)$ & \\
\hline Insatisfeito & $9(56,3 \%)$ & $7(43,8 \%)$ & \\
\hline \multicolumn{3}{|l|}{ Apoio Social } & \multirow[t]{3}{*}{0,030} \\
\hline Boa Rede Social & $63(85,1 \%)$ & $11(14,9 \%)$ & \\
\hline Rede Social Insuficiente & $17(65,4 \%)$ & $9(34,6 \%)$ & \\
\hline \multicolumn{3}{|l|}{ Osteoporose } & \multirow[t]{3}{*}{0,009} \\
\hline Ausente & $66(85,7 \%)$ & $11(14,3 \%)$ & \\
\hline Presente & $14(60,9 \%)$ & $9(39,1 \%)$ & \\
\hline
\end{tabular}

Fonte: Elaboração própria.

*Há indício de associação estatística nos casos em que o P-Valor for menor do que 0,05. 


\section{Discussão}

Acredita-se que a relevância do presente estudo consiste no fato de que são raras as pesquisas sobre Espiritualidade, Religiosidade e Crenças Pessoais (ERCP), além de sobre a saúde dos idosos longevos no Brasil. Assim, optou-se por estudar os determinantes da ERCP, uma vez que apresenta um valor intrínseco para a avaliação em saúde.

Diante das perdas e da finitude da vida, há uma maior necessidade de autocompreensão e de sentido, e uma das formas de enfrentar a resistência a tal crise existencial é a transformação interior. Mediante a espiritualidade, a religiosidade e as crenças pessoais é possível encontrar apoio e oportunidades para refletir, superando, assim, as perdas (FARINASSLO, 2012).

Neste estudo, foi encontrado um maior número de mulheres, o que expressou claramente o processo de feminização da velhice, ou seja, quanto mais a população envelhece, mais feminina ela se torna, e isto corroborou com diversos outros estudos que abordam sobre este tema (BELO, 2013; IBGE, 2011).

De acordo com o IBGE (2011), uma análise da atual transição demográfica brasileira na perspectiva de gênero mostra esse processo de feminização de forma bastante acentuada. Em 2011, as mulheres representavam $55,5 \%$ da população idosa brasileira e $61 \%$ do contingente de idosos acima de 80 anos. Este fenômeno é explicado através da maior expectativa de vida das mulheres, que, em média, vivem oito anos a mais do que os homens. Além disto, destacam-se as causas externas (assassinatos e acidentes), cujas vítimas, em sua grande maioria, são homens. E ainda existe o fato de o acompanhamento médico contínuo ocorrer com maior frequência entre as mulheres (mais de 90\% dos casos) do que entre os homens (BANDEIRA, 2010).

Em relação à religiosidade, os significados de religião geralmente estão associados à afiliação religiosa, a cultura e dogmas, e a maioria dos indivíduos autorreferiu sua religião. Isso também foi encontrado no estudo multicêntrico Saúde, Bem-Estar e Envelhecimento (Sabe), sobre o perfil religioso e a importância dada à religião pelos idosos no município de São Paulo (SP), associado às condições de saúde, revelando que, em 2006, 98\% dos idosos faziam parte de uma religião. Esta afiliação religiosa também vem acompanhada de uma ideia de pertencimento, assim como de uma interação social, permitindo a troca de informações entre o grupo, remetendo ao acolhimento (SOUZA, 2011).

Em estudo realizado por Moraes (2007), a importância da religião e sua prática relacionada com a qualidade de vida foram positivamente avaliadas por 50 indivíduos, entre 65 e 86 anos. A religiosidade foi considerada extremamente importante para a vida deles, dando-lhes força para suportar problemas, perdas e lutas. Além disso, os idosos relataram que o contato com o divino é importante, pois traz segurança e dá conforto espiritual.

Estudos prévios realizados por Peteet (2013) e Khorami (2013) evidenciaram que muitos pacientes têm buscado recursos espirituais e religiosos, a fim de melhorarem a sua satisfação com a vida. Na amostra, foi verificado que esta satisfação com a vida foi fortemente relacionada com as facetas paz e totalidade \& integração. Estes dados corroboram os dados encontrados por outro estudo, no qual se verificou que, para alguns idosos, a espiritualidade influencia todos os aspectos e momentos de seu viver diário, o que interfere em como se sentem emocional e também fisicamente (CHAVES, 2015).

Ressalta-se, ainda, outro estudo de revisão, realizado por Moreira-Almeida (2006), através do qual identificou-se que, para os idosos, a vivência espiritual, por meio de suas crenças pessoais, confere satisfação com a vida, através da esperança, à medida que conseguem desenvolver expectativas positivas e enfrentar a realidade e as incertezas do futuro.

A hipótese mais aceita é a de que a ERCP esteja associada a uma melhor qualidade de vida, sendo que um dos mecanismos 
mediadores prováveis é o estímulo a uma sensação de maior autonomia perante a vida (MACILVAINE, 2013).

Estudo realizado por Chaves (2015) verificou que o apoio social foi relacionado à ERCP, tanto no domínio WHOQOL-SRPB como nas facetas paz e totalidade \& integração, isoladamente, dado encontrado por outro autor, por quem o apoio social foi visto como fator preditor para a ERCP, em estudo realizado com idosos longevos no Brasil.

Além disso, a frequência à igreja promove apoio social e é atividade regular para muitos idosos (FLORIANO, 2007). Em estudo com 426 idosos de uma comunidade do Canadá, observou-se que os fatores preditores mais fortes para a qualidade de vida foram o apoio social e a satisfação com a saúde, sendo influenciados pelo convívio proporcionado pela adesão a uma comunidade religiosa (MOLZAHN, 2007).

Percebe-se que os idosos que não eram diabéticos e não possuíam osteoartrose apresentaram maior escore na análise da ERCP, na faceta totalidade \& integração. Segundo Seybold (2007), a ERCP também parece influenciar os processos fisiológicos, relacionados aos sistemas cardiovascular, neuroendócrino e imunológico, promovendo benefícios na saúde dos indivíduos. Para alguns, sua vida espiritual os auxilia na manutenção, promoção e restauração da saúde, através de sua relação ou conexão com o Ser Superior (CHAVES, 2015).

Os pacientes encontram na oração, meditação e/ou reflexão, formas de obterem maior conforto físico, psicológico e social. Eles afirmaram que isso lhes proporcionava um maior bem-estar, muitas vezes resultando em alívio de alguns sintomas físicos, como a dor (CAMARGOS ET AL., 2015).

Também observou-se que os idosos que não possuíam depressão experimentavam os mais altos índices de sentido na vida, corroborando com Costa (2013). Isso representou 158 idosos, na verificação da relação religiosidade/espiritualidade como preditora de qualidade de vida, tendo revelado que as facetas conexão com Ser Superior, sentido na vida, força espiritual, fé e espiritualidade apresentaram correlações significativas nos participantes com idades mais elevadas.

Segundo Moreira (2014), provavelmente a busca pelo sentido da vida é frutífera graças ao relacionamento do indivíduo com o sagrado, este que, na religiosidade, tem o papel de oferecer valores para a vida, e na espiritualidade, é uma experiência de significação da vida. Para Jung (1971), a velhice deve ser marcada por uma atenção específica e uma valorização, por parte do ser humano, do que está dentro de si, buscando, assim, um propósito para a vida. A valorização das crenças em busca do alcance do significado, na vida, potencializa a magnitude da espiritualidade para os idosos (KOENIG, 2012).

\section{Conclusões}

O estudo apresentou algumas limitações, que precisam ser levadas em consideração na interpretação dos resultados. Isso porque se tratou de um estudo transversal, no qual as relações de causa e efeito não podem ser determinadas; a população era muito homogênea, do ponto de vista étnico, apesar da amostra ter sido criteriosamente selecionada para excluir os fatores de confusão na análise. $\mathrm{O}$ fato de as entrevistas terem sido realizadas nas residências dispensou um maior tempo para as coletas, ocasionando dificuldades operacionais para a obtenção da amostra.

Acredita-se que esta análise contribuiu para preencher as lacunas dos outros estudos encontrados. Foi mostrado, estatisticamente, que a satisfação com a vida, o apoio social, o sentido na vida e a ausência de doenças crônicas estão associados a melhores níveis de ERCP. Também ficou comprovado que aspectos religiosos e não religiosos da espiritualidade, crenças e práticas espirituais desempenham um papel 
importante na manutenção do bem-estar dos idosos longevos.

Considerando o que foi encontrado na literatura sobre a importância da ERCP nos idosos e os importantes achados deste estudo, recomenda-se, aos profissionais de saúde, que priorizem o cuidado do ser humano, do ponto de vista integral, resgatando os valores subjetivos e respeitando os aspectos espirituais e religiosos que cada um carrega consigo, isto servindo de alicerce para a tomada de decisões, por ser uma parte poderosa do processo de cura.

Com base nos dados encontrados no estudo, sugere-se a ampliação das investigações sobre

\section{Referências}

BANDEIRA, L.; MELO, H. P.; PINHEIRO, L. S. Mulheres em dados: o que informa a PNAD/IBGE, 2008. Revista do Observatório Brasil da Igualdade de Gênero, Brasília, DF, p. 107-119, jul. 2010. Disponível em: <http://www.observatoriodegenero.gov.br/menu/ publicacoes $>$. Acesso em: 12 jun. 2017.

BELO, I. Velhice e mulher: vulnerabilidade e conquistas. Revista Feminismos da UFBA, Salvador, v. 1, n. 3, set./dez. 2013.

BRITO, T. A. et al. Quedas e capacidade funcional em idosos longevos residentes em comunidade. Texto contexto - Enfermagem, Florianópolis, v. 22, n. 1, p. 43-45, 2013. esta temática, mediante não somente a discussões sobre as possibilidades de colaboração na qualidade de vida dos idosos, mas também através da subsidiação de políticas públicas na atenção às pessoas idosas.

\section{Colaboradores}

Todos os autores deste manuscrito contribuíram substancialmente para a concepção e o planejamento, para a análise e a interpretação dos dados, bem como para a elaboração do rascunho ou revisão crítica do conteúdo, participando da aprovação de sua versão final.
CAMARGOS, M. G. et al. Understanding the Differences Between Oncology Patients and Oncology Health Professionals Concerning Spirituality/ Religiosity. Medicine (Baltimore, Md.), Baltimore, v. 94, n. 47 , p. $2145,2015$.

COSTA, F. B.; TERRA, N. L. Espiritualidade, religiosidade e qualidade de vida em idosos. Revista Geriatria \& Gerontologia, Rio de Janeiro, v. 7, n. 3, p. 173-178, 2013.

CHAVES, L. J.; GIL, C. A. Concepções de idosos sobre espiritualidade relacionada ao envelhecimento e qualidade de vida. Ciência \& Saúde Coletiva, Rio de Janeiro, v. 20 , n. 12 , p. $3641-3652,2015$. 
CUNHA, J. X. P. et al. Autonomia do idoso e suas implicações éticas na assistência de enfermagem. Saúde em Debate, Rio de Janeiro, v. 36, n. 95, p. 657-664, 2012.

FARINSASSO, A. L. C.; LABATE, R. C. Luto, religiosidade e espiritualidade: um estudo clínico-qualitativo com viúvas idosas. Revista Eletrônica de Enfermagem, Goiânia, v. 14, n. 3, p. 588-595, 2012.

FLORIANO, P. J.; DALGALRARRONDO P. Saúde mental, qualidade de vida e religião em Idosos de um Programa de Saúde da Família. Jornal Brasileiro de Psiquiatria, Rio de Janeiro, v. 56, n. 3, p. 162-170, 2007.

\section{INSTITUTO BRASILEIRO DE GEOGRAFIA E}

ESTATÍSTICA (IBGE). Sinopse do Senso Demográfico de 2010. Rio de Janeiro: IBGE, 2011. Disponível em: $<$ http://biblioteca.ibge.gov.br/visualizacao/periodicos/94/cd_2010_religiao_deficiencia.pdf $>$. Acesso em: 12 jun. 2017.

JUNG, C. G. A natureza da psique. Petrópolis: Vozes; 1971.

KHORAMI, M. A.; YAGHMAEI, F.; KHODAYARI, F. M. Spirituality as experienced by Muslim oncology nurses in Iran. Revista BR J Nurs., Londres, v. 22, n. 4, p. 22-24, 2013.

KOENIG, H. G. Medicina, Religião e Saúde: o encontro da ciência e da espiritualidade. Porto Alegre: L\&PM, 2012.

MACILVAINE W. R. et al. Association of strength of religious adherence to quality os life measures. Complement Ther Clin Pract., Londres, v. 19, n. 4, p. 251-255, 2013

MELLO, M. A.; ARAUJO, C. A. Velhice e espiritualidade na perspectiva da Psicologia Analítica. Boletim Academia Paulista de Psicologia, São Paulo, v. 33, n. 84, p. 118-141, 2013.

MOLZAHN, A. E. Spirituality in Later Life: effect on quality of life. J Gerontol Nurs, Nova Iorque, v. 33, n. 1, p. 32-39, 2007.
MORAES, N. A. S.; WITTER, G. P. Velhice: qualidade de vida intrínseca e extrínseca. Bol Psicol, São Paulo, v. 57, n. 127, p. 215-238, 2007.

\section{MOREIRA-ALMEIDA, A.; LOTUFO NETO, F.;} KOENIG, H. G. Religiousness and mental health: a review. Rev Bras Psiquiatr, São Paulo, v. 28, n. 3, p. 242250, 2006.

\section{MOREIRA, J. O.; FREITAS, A. C. P.; FIGUEIREDO,}

R. V. Algumas Considerações sobre Velhice BemSucedida na Perspectiva de Professores Universitários Brasileiros. Revista de Psicologia da UFC, Fortaleza, v. 5, n. 1, p. 21-31, 2014.

PETTET, J. R.; BALBONI, M. J. Spirituality and religion in oncology. CA Cancer J Clin, Nova Iorque, v. 63, n. 4, p. 280-289, 2013.

ROHR, F. Espiritualidade e Formação Humana. Poiésis, Tubarão, v. 1, n. esp., p. 53-68, 2011.

SEYBOLD, K. S. Physiological mechanisms involved in religiosity/spirituality and health. J Behav Med, Nova Iorque, v. 30, n. 4, p. 303-309, 2007.

MAIA, F. O. M.; DUARTE, Y. A. O.; LEBRAO, M. L. Análise dos óbitos em idosos no Estudo SABE. Revista da Escola de Enfermagem da USP, São Paulo, v. 40, p. 540-547, 2006.

VECCHIA, R. D. et al. Qualidade de vida na terceira idade: um conceito subjetivo. Revista Brasileira de Epidemiologia, São Paulo, v. 8, n. 3, p. 246-252, 2005.

VOLCAN, S. M. S. et al. Relação entre bem-estar espiritual e transtornos psiquiátricos menores: estudo transversal. Revista de Saúde Pública, São Paulo, v. 37, n. 4, p. 440-445, 2003.

Recebido para publicação em junho de 2017

Versão final em setembro de 2017

Conflito de interesses: inexistente

Suporte financeiro: não houve 